\title{
An introduction to mashups for health librarians
}

\author{
Allan Cho
}

\section{Introduction}

This paper discusses mashups, medical mashups for health librarians, specifically. Mashups bring together two or more Web applications to produce a completely new information service. Put another way, a mashup is a hybrid that takes two information sources and merges them to create a third, more useful tool. A good example of a widely used mashup is Google Maps (http://www.google.com/apis/ maps), which combines Google Earth data with telephone directory information to create a useful satellite road map.

Although they are part of Web 2.0 and share Web 2.0's openness, participation, and collaborative aspects, mashups build on a technological base dating back to the earliest days of the Web. By utilizing publicly available and open source code, mashups draw on current awareness tools like Web feeds, really simple syndication (RSS) or Atom, and JavaScript. While still experimental, mashups are worthy of close examination by health librarians interested in exploring new, creative methods of information delivery.

\section{What is Web 2.0?}

To understand mashups as a feature of Web 2.0, Tim O'Reilly's definition [1] may serve as a useful starting point for our discussion:

\begin{abstract}
Web 2.0 is the [Web] as platform, spanning all connected devices; Web 2.0 applications are those that make the most of the intrinsic advantages of that platform: delivering software as a continually-updated service that gets better the more people use it, consuming and remixing data from multiple sources, including individual users, while providing their own data and services in a form that allows remixing by others, creating network effects through an "architecture of participation", and going beyond the page metaphor of Web 1.0 to deliver rich user experiences.
\end{abstract}

Simply put, Web 2.0 applications utilize social software technologies. They encourage group interaction in a space where individuals can participate, socialize, and set social norms. Web 2.0 is characterized by online and real-time conversations with individuals who share similar interests and

A. Cho. School of Library, Archival and Information Studies, University of British Columbia, Suite 301, 6190 Agronomy

Road, Vancouver, BC V6T 1Z3, Canada

(e-mail: allancho@gmail.com;

blog: http://www.allanslibrary.blogspot.com). goals. Social software has moved the Web from a "readonly" technology to an open platform where users can "read-write-and-participate" [2].

Health librarians have written about several Web 2.0 services, such as blogs, RSS feeds, tagging, and podcasting [35]. Mashups, however, have not appeared in the health library literature (one American health librarian [6] has announced on her blog that her paper on mashups will be published in a forthcoming issue of Medical Reference Services Quarterly). This paper examines mashups and explores some representative examples as a means of evaluating the technology for health librarians.

\section{Mashups}

The evolution of mashup technology is the next stage of Web 2.0. Originally a term used in pop music by artists and disc jockeys when two songs were remixed and played at the same time, Web experts have borrowed the term when two or more software tools are merged. The resulting new tool provides an enriched Web experience for end-users.

Like other social software, mashups are freely accessible. Prior to the social software movement, only programming experts with training in $\mathrm{C}++$ or Visual Basic could publish complex Web sites. In contrast, a simple mashup can be created for free in less than $15 \mathrm{~min}$; expert technical skills are not required [7]. While mashups have put Web publishing into the hands of nontechnical users, they require some creativity on the part of developers as the following examples illustrate.

\section{Mashups for health libraries}

While the number of mashups is increasing, estimated at 2.63 per day [7], there is only a handful of applications in health and medicine (Table 1). Many of these mashups use Google maps, because the visual aspect of Web navigation is critical in Web 2.0. With only a few health mashups available, however, these simple but representative examples offer the health librarian some possibilities of where the technology is heading.

\section{Vimo}

Considered the first health care products and services mashup, Vimo (http://www.vimo.com) is an integrated comparison-shopping portal released in January 2006. It allows US businesses and consumers to research, rate, and purchase health insurance and health savings accounts, and selects physician profiles from across the US. Vimo brings together 
Table 1. Medical mashup matrix.

\begin{tabular}{|c|c|c|}
\hline Mashup and Web address & Description & API \\
\hline $\begin{array}{l}\text { Berkeley-area Doctors } \\
\text { (http://www.chaddickerson.com/mashups/doctors/) }\end{array}$ & $\begin{array}{l}\text { Searches for doctors in the Berkeley, California, } \\
\text { area }\end{array}$ & $\begin{array}{l}\text { Yahoo! Maps + Screen } \\
\text { Scraped Healthcare } \\
\text { Provider }\end{array}$ \\
\hline Vimo (http://www.vimo.com) & $\begin{array}{l}\text { Allows businesses and consumers to research, } \\
\text { rate, and purchase health insurance plans and } \\
\text { health savings accounts, and selects physician } \\
\text { profiles from across the US }\end{array}$ & Google Maps \\
\hline Biowizard (http://www.biowizard.com) & $\begin{array}{l}\text { Users can customize a personal profile on the } \\
\text { Lab Wizard Network, list publications, share } \\
\text { research interests, join groups, upload photos, } \\
\text { and chat live with others on the system }\end{array}$ & NCBI Entrez \\
\hline HEALTHmap (http://healthmap.org) & $\begin{array}{l}\text { Offers comprehensive view of the current global } \\
\text { state of infectious diseases and their effects } \\
\text { on human and animal health }\end{array}$ & Google Maps \\
\hline
\end{tabular}

Note: API, application programming interface.

a variety of private-public data sources so that health consumers can find physicians while comparing prices for procedures at each hospital. Vimo allows users to read and post reviews about the services and products available. Using Google Map's application programming interface (API) technology, Vimo searches for the exact location of a health professional's office when users click names on the Google map.

Using RSS feeds, Vimo automatically updates users about changes affecting physicians, including reviews, licenses, malpractice awards, or disciplinary actions. Vimo helps US residents to discover what health insurance plans are accepted by specific doctors. Although geared towards American consumers, the Vimo example may offer some possibilities for Canadian health consumers.

\section{HEALTHmap}

HEALTHmap (http://healthmap.org) brings different data sources together to achieve a unified and comprehensive view of the current global state of infectious diseases and their effects on human and animal health. It also combines Google Maps and RSS feeds from different news sources, including Google News, ProMED, the World Health Organization, and Euro Surveillance. Through an automated textprocessing system, the data is aggregated by disease and displayed by location for user-friendly access to the original alert. HEALTHmap may be invaluable for health professionals and librarians who want to stay up-to-the-minute with information on global health news.

\section{Biowizard}

Although the Biowizard (http://www.biowizard.com) search engine, PubMed Wizard, conducts search results identical in style to PubMed, its design goes beyond traditional searching. PubMed Wizard allows users to save, share, rank, and discuss selected articles. Biowizard is also an on- line social network where researchers registered with an account can customize a personal profile on the Lab Wizard Network, list publications, share research interests, join groups, upload photos, and even chat live with others on the system. Biowizard encourages user participation and collaboration through its highly interactive forums and features.

\section{Hypothetical medical mashup}

The following is a hypothetical medical mashup called The Talking Librarian, created using a number of free APIs.

$$
\begin{aligned}
\text { Skype talk } & + \text { Google Maps }+ \text { Flickr }+ \text { Technorati } \\
& + \text { Del.icio.us }=\text { The Talking Librarian }
\end{aligned}
$$

What are our goals with this mashup? Our goals are to connect health librarians from distant geographic regions and share local information within a global virtual network. How would it work?

Start with Skype; a librarian in Vancouver, B.C., unable to answer a health reference question about IV drug use in London, England, seeks assistance from a British librarian who might have the answer in her collection. Skype is used as the communication tool; Google Maps is used as a visual interface. Health librarians can scroll through Web pages on the Talking Librarian to find an available colleague while Flickr displays their individual photographs, hours of availability, and whether they are online. If that were not enough, Technorati can be used to list their participating Web sites and blogs. Del.icio.us tags can be listed to allow efficient sharing of bookmarked Web sites.

D. Giustini, personal communication, 2006.

This hypothetical mashup, The Talking Librarian, illustrates the possibilities available when combining successive layers of free Web services. This example is a glimpse of where mashups might be headed in the future. 
Figure 1. Google Maps and Starbucks mashup [8].

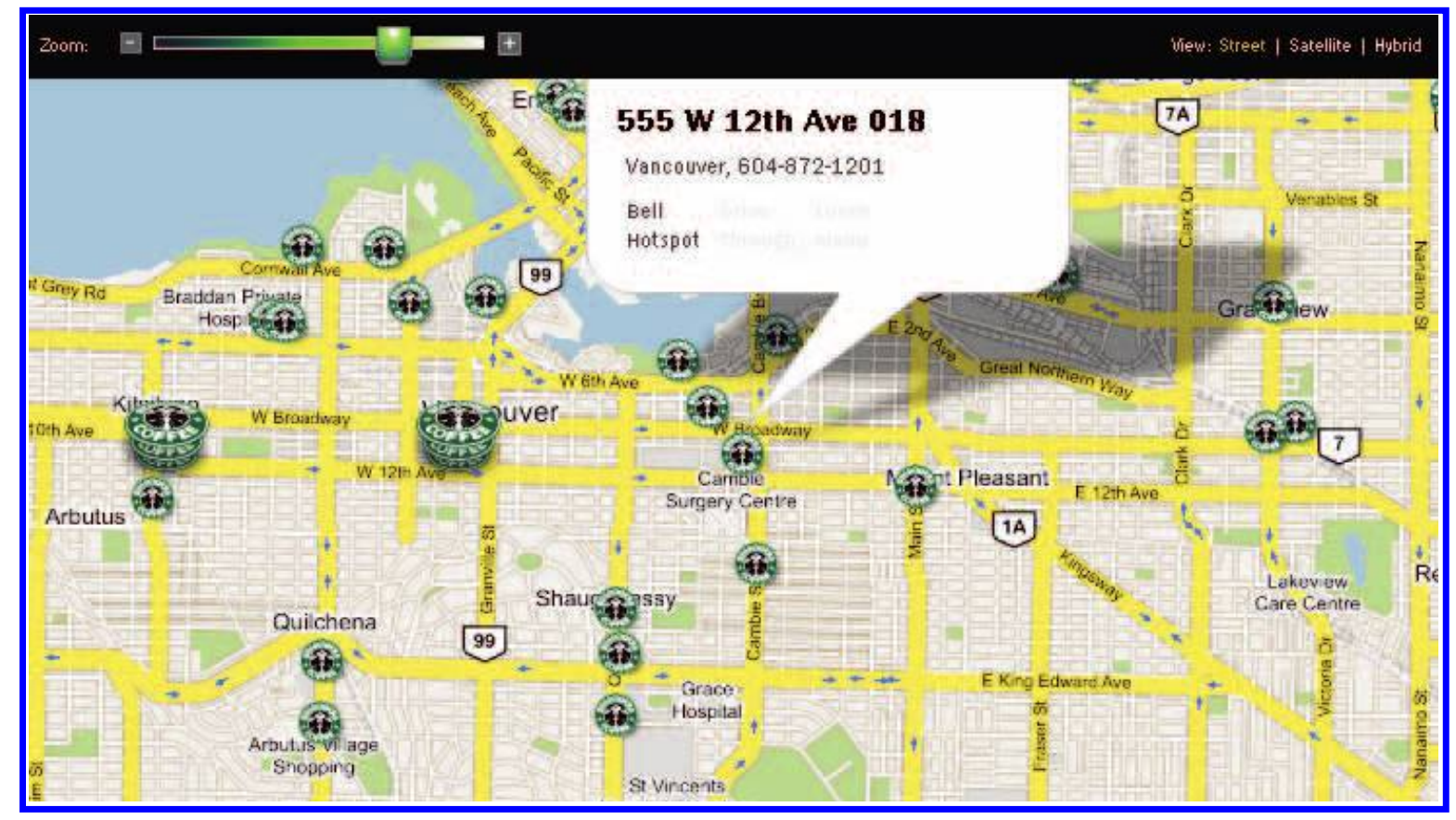

\section{Google API mashed with Starbucks locations in} Vancouver

Figure 1 illustrates a simple mashup in which Google Maps is used as the underneath "layer" (using its API key). Data is entered into the mashup to indicate particular Starbucks locations, while Google Maps provides the visual interface with latitudinal and longitudinal coordinate information.

\section{Health libraries and full participation in Web 2.0}

Health libraries face a number of challenges to fully participate in the creation of information sources in Web 2.0. One challenge is to find enough time to learn about Web 2.0 while keeping current with search technologies and publishing trends. That said, whether health librarians can adopt new technologies to move health libraries into the future and strengthen relationships with users - is an important question open to debate. Clearly, some of these technologies will not, over the long term, survive.

The American health librarian Michelle Kraft, who writes the Krafty Librarian blog, argues that a great number of hospitals discourage and prohibit Web 2.0 tools from being used on their computer networks. For example, some hospital firewalls block multimedia and do not permit their use on library computers. Kraft points out that there are a number of libraries that cannot create their own intranet (or Internet) library Web pages. Some librarians are required to use an institutional content management system that prevents users from viewing and editing, let alone supporting the notion of social software. Because host institutions have control over new Web technologies, these medical libraries are limited in their adoption and use of new software. Some hospital librarians feel their institution actively prevents technological progress in the interest of data security [9].

\section{Conclusion}

Health librarians are beginning to embrace the social software movement as they have other technological movements. Information specialist Matthew Dames says that few information professionals are as knowledgeable about building communities of learners as librarians are [10]. As laboratories of learning, health libraries are potential meeting places where clinicians can assemble to solve complex information problems together. With the number of patrons entering libraries decreasing due to online access to collections, social software tools can be utilized to extend health librarians' reach beyond their in-house collections and information services [10].

Social software tools such as mashups allow librarians to "reclaim" areas of influence and expertise in the organization that have been ceded to information technology departments [10]. To ensure that they remain relevant, health librarians can demonstrate their value by helping users to collaborate with each other. New social software applications such as mashups can increase the profile of health librarians and demonstrate to administrators that the library is a centre for innovation [10].

The health librarian's main purpose is to serve a community of health professionals, patients, and other users. Although social software tools are still relatively new technologies, forward-looking health librarians are demonstrating that they can harness their potential to provide innovative information services to users. Mashups are one of a number of new Web 2.0 tools that health librarians can evaluate as they are made more widely available.

\section{References}

1. O'Reilly T. Web 2.0: compact definition? O'Reilly Radar [Weblog]. Sebastopol, Calif.: O’Reilly Media. 2005 Oct 1 
[cited 2006 Dec 18]. Available from http://radar.oreilly.com/ archives/2005/10/web_20_compact_definition.html.

2. Harder G. Connecting the dots: social software and the social nature of libraries. Feliciter. 2006;52(2):54-5.

3. Barsky E. Introducing Web 2.0: weblogs and podcasting for health librarians. JCHLA. 2006;27(2):33-4.

4. Barsky E. Introducing Web 2.0: RSS trends for health librarians. JCHLA. 2006;27(1):7-8.

-5. Barsky E, Purdon M. Introducing Web 2.0: social networking and social bookmarking for health librarians. JCHLA. 2006;27(3):65-7.

6. Kraft M. Brief note on mashups. Krafty Librarian [Weblog]. San Francisco, Calif.: Blogger Inc. 2006 Nov 27 [cited 2006 Dec 25]. Available from http://kraftylibrarian.blogspot.com/ 2006/11/brief-note-on-mashups.html.

7. David B. Mashup ecosystem poised to explode. ZDNet [homepage on the Internet]. San Francisco: Calif.: CNET Networks, Inc. 2006 Jan 27 [cited on 2006 Nov 15]. Available from http://blogs.zdnet.com/BTL/?p=2484.

8. Findbyclick Coffee [homepage on the Internet]. Mississauga, Ont.: Pentura Solutions. 2006 Dec 29 [cited 2006 Dec 31]. Available from http://www.findbyclick.com/coffee_s.html.

9. Kraft M. Library 2.0 theory: Web 2.0 and its implications for libraries. The Krafty Librarian [Weblog]. San Francisco, Calif.: Blogger Inc. 2006 Aug 7 [cited 2006 Oct 12]. Available from http://kraftylibrarian.blogspot.com/2006/08/library20-theory-web-20-and-its.html.
10. Dames KM. Social software in the library. LLRX.com (Library Resource Xchange, $L L C$ ) [serial on the Internet]. 2004 July 26 [cited 2006 Nov 12]. Available from http://www.llrx.com/ features/socialsoftware.htm.

\section{Glossary}

Application programming interface (API) - API is a source code interface that a computer system provides to support requests for services to be made of it by a computer program (see http://en.wikipedia.org/wiki/API). A number of APIs are freely available for downloading, including Google Maps.

Blog - Also called a "weblog", a blog is a user-generated Web site where entries are made in journal style and displayed in reverse chronological order.

Google APIs - Google offers several APIs for Web and desktop programmers alike. They are often based around current Google products, including AdSense, Google Checkout, and Google Toolbar.

Mashup - A mashup is a Web site or application that seamlessly combines content from more than one source into an integrated experience.

Really simple syndication (RSS) - RSS is a family of Web feed formats used to publish frequently updated digital content, such as blogs, news feeds, or podcasts.

Web 2.0 - Web 2.0 refers to a perceived or proposed second generation of Internet-based services (social networking sites, wikis, blogs, communication tools, folksonomies) that emphasize online collaboration and sharing among users. 
This article has been cited by:

1. Eugene Barsky, Allan Cho. 2007. Introducing Web 2.0: social search for health librarians. Journal of the Canadian Health Libraries Association 28:2, 59-61. [Abstract] [PDF] [PDF Plus] 